\title{
Effects of layering technique on the shade of resin overlays and the microhardness of dual cure resin cement
}

\begin{abstract}
Hoon-Sang CHANG(a) Sung-Ok HONG(b)
\end{abstract}

(a) Department of Conservative Dentistry, School of Dentistry, Chonnam National University, Gwangiu, Korea.

(b) Department of Conservative Dentistry, School of Dentistry, Wonkwang University, Iksan, Korea.

Declaration of Interests: The authors certify that they have no commercial or associative interest that represents a conflict of interest in connection with the manuscript.

Corresponding Author:

Hoon-Sang Chang

E-mail: conden@inu.ac.kr

DOI: 10.1590/1807-3107BOR-2014.vol28.0016 Epub Jun 02, 2014

Submitted: Nov 28, 2013

Accepted for publication: Feb 18, 2014

Last revision: Apr 22, 2014

\begin{abstract}
The purpose of this study was to assess the color of layered resin overlays and to test the early microhardness of dual cure resin cement (DCRC) light cured through the layered resin overlays. Resin overlays of $1.5 \mathrm{~mm}$ thickness were fabricated with the A3 shade of Z350 (Group 1L), the A3B and A3E shades of Supreme XT (Group 2L), and the A3, E3, and T1 shades of Sinfony (Group 3L) using one, two, and three layers, respectively $(n=7)$. Each layer of the resin overlays was set in equal thickness. The color of the resin overlays was measured with a colorimeter and compared with an A3 shade resin denture tooth. DCRC was light cured through the resin overlays, and the early microhardness of the DCRC was measured. The $\triangle \mathrm{E}$ value between the denture tooth and the resin overlays and the Vickers hardness number (VHN) of the DCRC were analyzed with one-way ANOVA and Tukey's HSD test. The color differences were $8.9 \pm 0.5,5.3 \pm 1.0$, and $7.3 \pm 0.5$ and the VHNs were $19.4 \pm 1.1,21.1 \pm 0.9$, and $29.3 \pm 0.6$ for Groups $1 \mathrm{~L}, 2 \mathrm{~L}$, and $3 \mathrm{~L}$, respectively. Therefore, to match the designated tooth color of resin inlays and to increase the early microhardness of DCRC, layered resin inlays are more appropriate than single-dentin-layer resin inlays. However, the translucent layer should be used cautiously because the color difference of resin inlays with a translucent layer was affected more than those without a translucent layer.
\end{abstract}

Keywords: Color; Composite Resins; Hardness Tests.

\section{Introduction}

Dual cure resin cements (DCRCs) are intended to polymerize when they are exposed to curing light and when the base and catalyst components are mixed together. ${ }^{1}$ However, most DCRCs still require light activation and have demonstrated insufficient hardness when light curing was omitted or attenuated by the tooth structure or the restoration. ${ }^{2,3,4}$ The hardness of DCRCs was investigated, and it was reported that the thickness as well as the shade of the resin or ceramic inlays could affect the hardness of the resin cement. 5,6

Esthetics in the posterior region are not as critical as in the anterior region, and the shade guides of many direct resin composite systems recommend using a single dentin layer or dentin and enamel layers for posterior restorations. Some indirect resin composite systems are composed of dentin, enamel, and translucent layers, and manufacturers recommend 
using a layering technique for posterior restorations. The layering technique attempts to replace dentin and enamel by placing a more translucent layer over a more opaque layer of resin composite to create a perception of depth from within the restoration. ${ }^{7}$ However, studies have reported poor compatibility of resin composites of identical shade designation between pairs of shades, ${ }^{8,9}$ and the color of the restoration was influenced by the optical properties of the enamel layer as well as those of the dentin layer.,10

On the other hand, incorporation of enamel and translucent layers on resin overlays increased curing light penetration through layered resin overlays. ${ }^{11}$ Higher curing light penetration could enhance the light curing of DCRC beneath the resin overlays. Polymerization of resin cement is usually assessed by hardness tests, ${ }^{12,13}$ and many studies on hardness measurements of DCRCs that were light cured through various indirect restorations were performed with one single shade. ${ }^{14,15}$ However, in clinical situations, resin inlays are usually fabricated with a layering technique. Studies on the hardness of DCRCs light cured through resin overlays with a layering technique are difficult to find. Therefore, the purpose of this study was to assess the final shade of resin overlays fabricated with a layering technique and to test the early microhardness of DCRC light cured through the layered resin overlays. The tested null hypothesis was that the layering technique had no effect on the final shade of the resin overlays and on the early microhardness of DCRC light cured through the resin overlays.

\section{Methodology Resin overlay fabrication}

Resin overlays of $15 \mathrm{~mm}$ diameter and $1.5 \mathrm{~mm}$ thickness were prepared in a custom-made cylindrical aluminum mold with a movable Teflon plate of $15 \mathrm{~mm}$ diameter inserted into the mold. A bolt was attached to the opposite side of the Teflon plate, so that the space inside the hole could be adjusted by the rotation of the bolt, which was marked in 10 steps such that one step corresponded to a downward movement of the Teflon plate by $0.1 \mathrm{~mm} .^{12}$

Single-layer resin overlays (Group 1L) were fabricated by lowering the Teflon plate by $1.5 \mathrm{~mm}$ and filling the empty space with Filtek Z350 (3M ESPE, St Paul, USA), shade A3. The upper surface of the aluminum mold was covered with a polyester film and a glass slab to press the surface for removal of the excess resin composite. The resin composite was light cured with a light-emitting diode (LED) light curing unit (LCU) (Elipar FreeLight 2, 3M ESPE, St Paul, USA) for 5 seconds. After removing the glass slab and the polyester film, the resin overlay was light cured for 20 seconds using an overlapping curing procedure to ensure that every part of the resin overlay was light cured.

Resin overlays with two layers (Group 2L) were fabricated by lowering the Teflon plate by $0.75 \mathrm{~mm}$ and filling the empty space with Filtek Supreme XT (3M ESPE, St Paul, USA), body shade A3B. After light curing as described previously, the Teflon plate was lowered by another $0.75 \mathrm{~mm}$, and Filtek Supreme XT, enamel shade A3E, was filled and light cured.

Resin overlays with three layers (Group 3L) were fabricated by sequential lowering of the Teflon plate by $0.5 \mathrm{~mm}$ for layers of Sinfony indirect lab composite (3M ESPE, Seefeld, Germany) dentin shade A3, followed by enamel shade E3, and translucent shade T1. Seven resin overlays were fabricated in each group $(n=7)$.

To analyze the color of each layer constituting the resin overlays, resin overlay specimens were fabricated each in a single layer of $1.5 \mathrm{~mm}$ thickness as described above $(n=7)$.

\section{Color measurement of resin overlays}

Commission International de l'Eclairage (CIE) $L^{*} a^{*} b^{*}$ values of the resin overlays were measured with a colorimeter (ShadeEye NCC, Shofu Inc., Kyoto, Japan) by contacting the measuring tip to the middle of the resin overlays. The colorimeter was set in 'Analyze mode', and before each color measurement, the instrument was calibrated with the white working standard provided by the manufacturer. The color measurement was processed in the lighting booth with $65 \mathrm{~K}$ illumination (Spectralight III Booth, GretagMacbeth, Newburgh, USA) over a standard white backing $\left(\mathrm{CIE} \mathrm{L}^{*}=96.6, \mathrm{a}^{*}=0.2, \mathrm{~b}^{*}=0.1\right)$. The color of a shade $\mathrm{A} 3$ resin denture tooth (Enduro Anterio, Shofu Inc., Kyoto, Japan, CIE L* $=72.4, a^{*}=-1.3, b^{*}=17.0$ ) 
was measured as a control. The color of the resin denture tooth was measured on the middle of the flat labial surface of the central incisor. ${ }^{16}$ The color difference $(\Delta \mathrm{E})$ between shade $\mathrm{A} 3$ of the resin denture tooth $\left(\mathrm{L}^{*}, \mathrm{a}^{*}{ }_{1}, \mathrm{~b}^{*}\right)$ and that of the resin overlays $\left(\mathrm{L}^{*}, \mathrm{a}^{*}{ }_{2}, \mathrm{~b}^{*}{ }_{2}\right)$ was calculated as follows: ${ }^{17}$

$$
\Delta \mathrm{E}=\left[\left(\mathrm{L}_{1}^{*}-\mathrm{L}_{2}^{*}\right)^{2}+\left(\mathrm{a}_{1}^{*}-\mathrm{a}_{2}^{*}\right)^{2}+\left(\mathrm{b}^{*}{ }_{1}-\mathrm{b}_{2}{ }^{*}\right)^{2}\right]^{1 / 2}
$$

\section{Early microhardness measurements of dual cure resin cement}

A custom-made aluminum mold with an inner diameter of $3 \mathrm{~mm}$ and a Teflon plate insert was used..$^{12}$ To control the light curing time of the DCRC, the diameter of the DCRC specimen was controlled to be smaller than the diameter of the light guide tip of the LCU. The Teflon plate in the mold was lowered by $1 \mathrm{~mm}$, and DCRC (RelyX Unicem, 3M ESPE, Seefeld, Germany) was mixed according to the manufacturer's instructions and filled into the empty space. The upper surface of the aluminum mold including the DCRC was covered with a polyester film and a previously fabricated resin overlay. To control the DCRC thickness to $1 \mathrm{~mm}$, a glass slab was used to put pressure on the upper surface of the mold. After removing the glass slab, the DCRC was light cured through the resin overlay with the LCU for 20 seconds according to the manufacturer's instructions. ${ }^{12}$ The power density of the LCU was measured at $1040 \mathrm{~mW} / \mathrm{cm}^{2}$ with a handheld dental radiometer (Cure Rite, Kerr, Milford, USA). After 10 minutes from the start of light curing, the Vickers microhardness of the DCRC was measured with a microhardness tester (MHT-10, Anton Paar, Graz, Austria) with a $100 \mathrm{~g}$ load for 10 seconds dwell time at 3 points in the center of the upper surface forming a small triangle, and the mean Vickers hardness number (VHN) was calculated. ${ }^{18}$ Seven DCRC spec- imens that were light cured through layered resin overlays were used for the microhardness tests $(n=7)$.

The CIE L*a*b* values of the resin overlays and their constituents, the $\Delta \mathrm{E}$ values between the denture tooth and the resin overlays, and the VHN of the DCRC were analyzed with one-way ANOVA at a 5\% significance level followed by post-hoc comparisons with Tukey's HSD test (SPSS 19.0, SPSS Inc., Chicago, USA).

\section{Results}

The CIE L*a*b* values of layered resin overlays and their constituents of $1.5 \mathrm{~mm}$ thickness are shown in Table 1 and Table 2, respectively. The $L^{*}$ value was higher in Group 3L compared to Groups 1L and 2L. The $a^{*}$ and $b^{*}$ values were higher in Group 1L compared to Groups 2L and 3L. In Table 2, the $\mathrm{L}^{*}$ value was highest in Sinfony T1 followed by Sinfony E3, and Z350 A3 had the lowest $L^{*}$ value. The $a^{*}$ value of Z350 A3 was highest, followed by the layer constituents of Supreme XT and Sinfony. The $b^{*}$ values were highest in Sinfony A3, Supreme XT A3B, and Z350 A3, followed by Supreme XT A3E, Sinfony E3, and Sinfony T1 $(p<0.05)$.

The $\Delta \mathrm{E}$ values between the shade $\mathrm{A} 3$ resin denture tooth and the resin overlays are shown in Figure 1. $\Delta$ E was $5.3 \pm 1.0$ for Group $2 \mathrm{~L}, 7.3 \pm 0.5$ for Group $3 \mathrm{~L}$, and $8.9 \pm 0.5$ for Group 1L $(p<0.05)$.

Table 1. Means and standard deviations of $L^{*}, a^{*}$, and $b^{*}$ values of layered resin overlays.

\begin{tabular}{lrrr}
\hline & \multicolumn{1}{c}{$1 \mathrm{~L}$} & \multicolumn{1}{c}{$2 \mathrm{~L}$} & \multicolumn{1}{c}{$3 \mathrm{~L}$} \\
\hline $\mathrm{L}^{*}$ & $75.8 \pm 0.5^{\mathrm{a}}$ & $75.3 \pm 1.1^{\mathrm{a}}$ & $78.9 \pm 0.8^{\mathrm{b}}$ \\
$\mathrm{a}^{*}$ & $2.2 \pm 0.1^{\mathrm{a}}$ & $1.7 \pm 0.2^{\mathrm{b}}$ & $-0.9 \pm 0.4^{\mathrm{c}}$ \\
$\mathrm{b}^{*}$ & $24.5 \pm 0.3^{\mathrm{a}}$ & $20.4 \pm 0.6^{\mathrm{b}}$ & $13.4 \pm 0.4^{\mathrm{c}}$ \\
\hline
\end{tabular}

Values followed by different superscript letters are significantly different $(p<0.05) .1 \mathrm{~L}=\mathrm{Z3} 50 \mathrm{~A} 3 ; 2 \mathrm{~L}=$ Supreme XT A3B \& A3E; 3L = Sinfony $A 3, E 3 \& T 1$

Table 2. Means and standard deviations of $L^{*}, a^{*}$, and $b^{*}$ values of each layer constituting resin overlays.

\begin{tabular}{|c|c|c|c|c|c|c|}
\hline \multirow{2}{*}{$\begin{array}{l}\text { Resin } \\
\text { Shade }\end{array}$} & \multirow{2}{*}{$\begin{array}{c}\text { Z350 } \\
\text { A3 }\end{array}$} & \multicolumn{2}{|c|}{ Supreme XT } & \multicolumn{3}{|c|}{ Sinfony } \\
\hline & & A3B & A3E & A3 & E3 & $\mathrm{Tl}$ \\
\hline$L^{*}$ & $75.8 \pm 0.5^{a}$ & $79.3 \pm 0.6^{c}$ & $78.5 \pm 0.4^{b}$ & $79.1 \pm 0.5^{b c}$ & $82.2 \pm 0.4^{\mathrm{d}}$ & $83.6 \pm 0.4^{e}$ \\
\hline$a^{*}$ & $2.2 \pm 0.1^{\circ}$ & $1.3 \pm 0.1^{b}$ & $0.6 \pm 0.2^{c}$ & $-0.3 \pm 0.1^{\mathrm{e}}$ & $0.1 \pm 0.2^{d}$ & $-0.4 \pm 0.2^{\mathrm{e}}$ \\
\hline$b^{*}$ & $24.5 \pm 0.3^{b}$ & $24.9 \pm 0.7^{a b}$ & $19.6 \pm 0.3^{c}$ & $25.5 \pm 0.6^{a}$ & $7.7 \pm 0.1^{d}$ & $2.7 \pm 0.2^{\mathrm{e}}$ \\
\hline
\end{tabular}

Values followed by different superscript letters are significantly different $(p<0.05)$. 


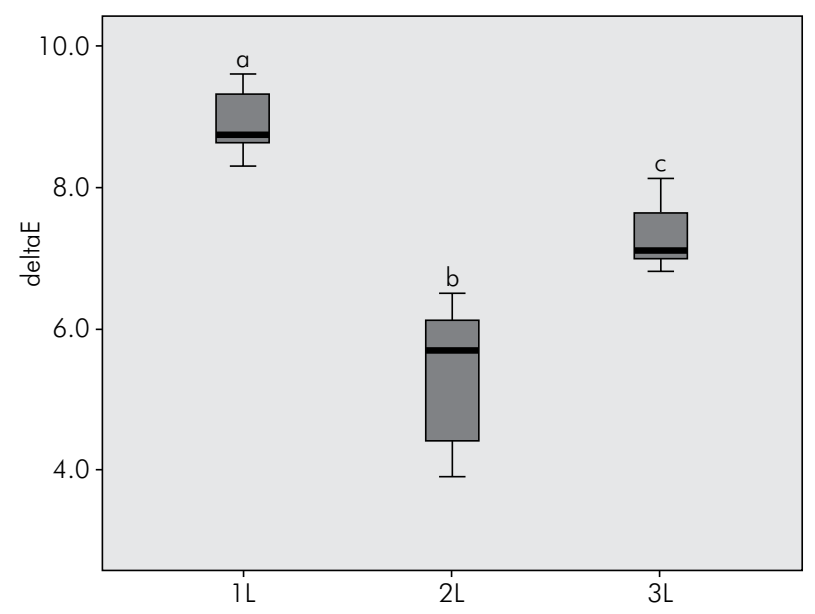

Figure 1. Color difference $(\Delta \mathrm{E})$ between a shade $\mathrm{A} 3$ resin denture tooth and layered resin overlays. $\Delta E$ value of the three groups was statistically significant $(p<0.05) .1 \mathrm{~L}=$ Z350 A3; $2 \mathrm{~L}=$ Supreme $\mathrm{XT}$ A3B \& A3E; 3L = Sinfony A3, E3 \& T1.

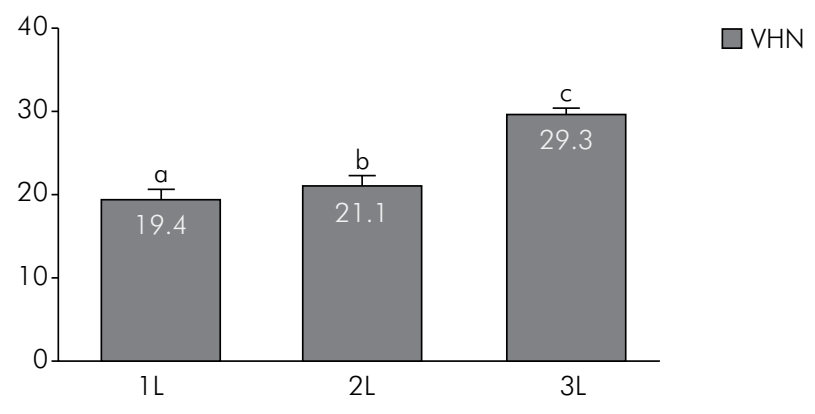

Figure 2. Vickers hardness number (VHN) of dual cure resin cement light cured through layered resin overlays. VHN of the three groups was statistically significant $(p<0.05) .1 \mathrm{~L}=Z 350$ A3; $2 \mathrm{~L}=$ Supreme XT A3B \& A3E; 3L = Sinfony A3, E3 \& T1.

The VHN of DCRC light cured through resin overlays is shown in Figure 2. The VHN of DCRC light cured through Group 3L was $29.3 \pm 0.6$, through Group 2L was $21.1 \pm 0.9$, and through Group $1 \mathrm{~L}$ was $19.4 \pm 1.1(p<0.05)$.

\section{Discussion}

Generally, resin inlays are fabricated with resin composites exclusively used by dental laboratories. However, some studies reported that the flexural strength and surface hardness of direct resin composite materials were superior to those of indirect resin composites. ${ }^{19,20}$ Therefore, direct resin composite systems were used for resin overlay fabrication with either a dentin layer or dentin and enamel layers and compared with indirect resin composite systems with dentin, enamel, and translucent layers. Because the incorporation of highly translucent enamel and translucent layers is reported to affect the final color of the resin overlays, ${ }^{7}$ the color of the resin overlays was measured and compared with a shade $\mathrm{A} 3$ resin denture tooth. In a previous study, a VITA Classical Shade tab was used as a control with the metal tab holder removed. ${ }^{16}$ However, the removal of the lingual part of the tab holder could affect the thickness of the shade tab, and thereby affect the color of the shade tab. In this study, a resin denture tooth was selected for the control because the lingual part of the denture tooth is similar in shape to that of a human tooth without any modifications that could affect the color measurement procedure.

The L* value of Group 3L was higher than that of the other groups, and this could be explained by the L* values of Sinfony T1 and Sinfony E3 being significantly higher than those of other constituents of resin overlays. The a* value was highest in Group 1L, followed by Group 2L and Group 3L. The a* values of Groups 1L and 2L were slightly positive, whereas that of Group 3L was slightly negative. In general, the $a^{*}$ values of the experimental groups were nearly neutral. The $b^{*}$ value was highest in Group $1 \mathrm{~L}$, followed by Group 2L and Group 3L. The $b^{*}$ value of the shades corresponding to dentin or body shades (Z350 A3, Supreme XT A3B, and Sinfony A3) were significantly higher than the shades corresponding to enamel shades (Supreme XT A3E, Sinfony E3 and Sinfony T1). Therefore, the resin overlays fabricated with enamel shades or enamel and translucent shades showed lower $b^{*}$ values. Furthermore, the thickness of the enamel plus translucent shades of Group 3L was $1.0 \mathrm{~mm}$, compared to Group 2L with an enamel thickness of $0.75 \mathrm{~mm}$, resulting in lower $b^{*}$ values.

When analyzing the CIE L*a* $b^{*}$ values of the individual shades, the range of $b^{*}$ values ( $2.7 \pm 0.2$ to $\left.25.5 \pm 0.6\right)$ was greater than those of $L^{*}$ values $(75.8 \pm 0.5$ to $83.6 \pm 0.4$ ) and $a^{*}$ values $(-0.4 \pm 0.2$ to $2.2 \pm 0.1)$. This implies that the dentin, enamel, and translucent shades of A3 are primarily dependent on the $b^{*}$ value rather than on $L^{*}$ or $\mathrm{a}^{*}$ values. Even the CIE L*a* $\mathrm{b}^{*}$ values were different among dentin shades and enamel shades. These shade 
variations might be due to various factors such as the amount, size, and shape of the filler. ${ }^{21}$ The filler content of Z350 and Supreme XT is $78.5 \%$ by weight, and the filler is composed of zirconia/silica of $0.6-1.4 \mu \mathrm{m}$. However, Z350 has added silica nanoparticles of $20 \mathrm{~nm}$, whereas Supreme XT has silica nanofiller of $5-75 \mathrm{~nm}$ in addition to the zirconia/silica. On the other hand, Sinfony is filled with aluminum glass and silica of $0.6 \mu \mathrm{m}$, and the filler content is $50 \%$ by weight. ${ }^{22} \Delta \mathrm{E}$ values between the resin denture tooth and Groups $1 \mathrm{~L}, 2 \mathrm{~L}$, and $3 \mathrm{~L}$ were $8.9 \pm 0.5,5.3 \pm 1.0$, and $7.3 \pm 0.5$, respectively. $\Delta \mathrm{E}=0 \sim 2$ is considered imperceptible, $\Delta \mathrm{E}=2 \sim 3$ just perceptible, $\Delta \mathrm{E}=3 \sim 8$ moderately perceptible, and $\Delta \mathrm{E}>8$ markedly perceptible. ${ }^{21}$ Therefore, the $\Delta \mathrm{E}$ of Group $1 \mathrm{~L}$ was markedly perceptible, and those of Groups 2L and 3L were moderately perceptible. These results are in accord with those of other studies on color measurements of resin composites. One study compared the enamel and dentin shades of resin composites with the VITA Classical Shade tabs and found that the range of $\Delta \mathrm{E}$ values was 0.9 to $12.8{ }^{8}$ Costa et al..$^{16}$ compared the final shade of resin composites prepared using the layering technique (enamel layer over dentin layer) with the corresponding VITA Classical Shade tabs and reported that only $28 \%(n=72)$ of layered resin composites resulted in $\Delta \mathrm{E}<3.3$, below the clinically perceptible limit.

To simulate the clinical situation of resin inlay cementation, the microhardness of DCRC was tested 10 minutes after the start of light curing the DCRC through resin overlays because resin inlays are adjusted, finished, and polished immediately following light curing DCRC, and these procedures can create stress affecting the adhesive cementation of resin inlays to tooth structure. ${ }^{1}$ The VHN increased when the enamel layer was added to the dentin layer and increased further when the translucent layer was added to enamel and dentin layers for resin overlay fabrication. This result is supported by our previous study using the same type of resin overlays and LCU. The power density of the LCU measured through Groups 1L, 2L, and 3L was $163 \pm 4 \mathrm{~mW} / \mathrm{cm}^{2}, 211 \pm$ $5 \mathrm{~mW} / \mathrm{cm}^{2}$, and $332 \pm 6 \mathrm{~mW} / \mathrm{cm}^{2}$, respectively. ${ }^{22}$ The power density of the LCU through resin overlays could be enhanced using enamel and translucent layers because these layers were less effective than the dentin layer in attenuation of the curing light. ${ }^{11,22}$ Therefore, the relatively higher translucency of the enamel and translucent layers, compared to that of the dentin layer, enhanced the curing light penetration through the resin overlays and thus increased the photopolymerization of the DCRC. Consequently, the null hypothesis could be rejected.

The limitation of this study was that the colorimeters, although commonly used in color measurement of teeth and tooth-colored restorations, have small apertures, and therefore have a tendency for edge-loss effects, which could lead to errors. ${ }^{23}$ Further studies might explore the combination of various shade layers with various thicknesses of individual layers for the fabrication of resin inlays to resemble the natural tooth color and simultaneously to increase the photopolymerization of the resin cements used for luting.

\section{Conclusion}

Resin overlays fabricated with a single dentin layer showed markedly perceptible color differences compared to a shade A3 resin denture tooth. Additionally, the early microhardness of DCRC light cured through resin overlays with a single dentin layer had the lowest VHN values. On the other hand, resin overlays with dentin and enamel layers and those with dentin, enamel, and translucent layers showed moderately perceptible color differences. However, the early microhardness of the DCRC was higher when it was light cured through resin overlays with dentin, enamel, and translucent layers compared to resin overlays with dentin and enamel layers. Therefore, to match the designated tooth color of resin inlays and to increase the early microhardness of DCRC through resin inlays, multilayered resin inlays seem to be more appropriate than single-dentin-layer resin inlays. However, translucent layers should be used cautiously because the color difference of resin inlays with translucent layers was more affected than those without a translucent layer.

\section{Acknowledgements}

This study was financially supported by the Chonnam National University, 2012. The authors thank $3 \mathrm{M}$ Korea for their generous donation of materials for this research. 


\section{References}

1. Arrais CAG, Giannini M, Rueggeberg FA. Kinetic analysis of monomer conversion in auto- and dual-polymerizing modes of commercial resin luting cements. J Prosthet Dent. 2009 Feb;101(2):128-36.

2. Hasegawa EA, Boyer DB, Chan DC. Hardening of dualcured cements under composite resin inlays. J Prosthet Dent. 1991 Aug;66(2):187-92.

3. Sigemori RM, Reis AF, Giannini M, Paulillo LA. Curing depth of a resin-modified glass ionomer and two resin-based luting agents. Oper Dent. 2005 Mar-Apr;30(2):185-9.

4. Braga RR, Cesar PF, Gonzaga CC. Mechanical properties of resin cements with different activation modes. J Oral Rehabil. 2002 Mar;29(3):257-62.

5. Calgaro PA, Furuse AY, Correr GM, Ornaghi BP, Gonzaga $\mathrm{CC}$. Influence of the interposition of ceramic spacers on the degree of conversion and the hardness of resin cements. Braz Oral Res. 2013 Sep-Oct;27(5):403-9.

6. ParkSH,KimSS, Cho YS, LeeCK, Noh BD. Curing units' ability to cure restorative composites and dual-cured composite cements under composite overlay. Oper Dent. 2004 Nov-Dec;29(6):627-35.

7. Kamishima N, Ikeda T, Sano H. Color and translucency of resin composites for layering techniques. Dent Mater J. 2005 Sep;24(3):428-32.

8. Park SK, Lee YK. Shade distribution of commercial resin composites and color difference with shade guide tabs. Am J Dent. 2007 Oct;20(5):335-9.

9. Paravina RD, Kimura M, Powers JM. Color compatibility of resin composites of identical shade designation. Quintessence Int. 2006 Oct;37(9):713-9.

10. Lee YK, Powers JM. Calculation of colour resulting from composite/compomer layering techniques. J Oral Rehabil. 2004 Nov;31(11):1102-8.

11. Hong S-O, Oh Y, Min J-B, Kim J-W, Lee B-N, Hwang Y-C, et al. Power density of various light curing units through resin inlays with modified layer thickness. Restor Dent Endod. 2012 Aug;37(3):130-5.

12. Chang HS, Kim JW. Early hardness and shear bond strength of dual cure resin cement light cured through resin overlays with different dentin layer thicknesses. Oper Dent. 2013 Nov 5. Epub ahead of print.
13. Hwang IN, Hong SO, Lee BN, Hwang YC, Oh WM, Chang HS. Effect of amulti-layer infection control barrier on the micro-hardness of a composite resin. J Appl Oral Sci. 2012 Sep-Oct;20(5):576-80.

14. Santos GB, Alto RV, Sampaio Filho HR, Silva EM, Fellows CE. Light transmission on dental resin composites. Dent Mater. 2008 May;24(5):571-6.

15. Bueno ALN, Arrais CAG, Jorge ACT, Reis AF, Amaral CM. Light-activation through indirect ceramic restorations: does the overexposure compensate for the attenuation in light intensity during resin cement polymerization? J Appl Oral Sci. 2011 Jan-Feb;19(1):22-7.

16. Costa J, Fox P, Ferracane J. Comparison of various resin composite shades and layering technique with a shade guide. J Esthet Restor Dent. 2010 Apr;22(2):114-24.

17. Nam SH, Lee HW, Cho SH, Lee JK, Jeon YC, Kim GC. Highefficiency tooth bleaching using non-thermal atmospheric pressure plasma with low concentration of hydrogen peroxide. J Appl Oral Sci. 2013 May-Jun;21(3):265-70.

18. Erdemir U, Yildiz E, Eren MM, Ozel S. Surface hardness evaluation of different composite resin materials: influence of sports and energy drinks immersion after a short-term period. J Appl Oral Sci. 2013 Mar-Apr;21(2):124-31.

19. Soares CJ, Pizi EC, Fonseca RB, Martins LR. Mechanical properties of light-cured composites polymerized with several additional post-curing methods. Oper Dent. 2005 May-Jun;30(3):389-94.

20. Borba M, Della Bona A, Cecchetti D. Flexural strength and hardness of direct and indirect composites. Braz Oral Res. 2009 Jan-Mar;23(1):5-10.

21. Yamanel K, Caglar A, Ozcan M, Gulsah K, Bagis B. Assessment of color parameters of composite resin shade guides using digital imaging versus colorimeter. J Esthet Restor Dent. 2010 Dec;22(6):379-88.

22. Chang H-S, Lim Y-J, Kim J-M, Hong S-O. [Power density of light curing units through resin inlays fabricated with direct and indirect composites]. J Korean Acad Conserv Dent. 2010 Sep;35(5):353-8. Korean.

23. Joiner A. Tooth colour: a review of the literature. J Dent. 2004 Jan;32 Suppl 1:3-12. 